\title{
Cactus Pear Fruit Extract Exerts Anti-Inflammatory Effects in Carrageenin-Induced Rat Pleurisy
}

\author{
M. Allegra, L. Tesoriere and M.A. Livrea \\ Dipartimento di Scienze e Tecnologie Biologiche, \\ Chimiche e Farmaceutiche \\ Università di Palermo \\ Italy
}

\author{
A. Ianaro and E. Panza \\ Dipartimento di Farmacologia \\ Sperimentale \\ Università di Napoli "Federico II" \\ Italy
}

Keywords: cactus pear fruit, indicaxanthin, phytochemicals, inflammation, in vivo

\begin{abstract}
Nutritional research has recently shifted from alleviating nutrient deficiencies to chronic disease prevention. In this study activity of cactus pear fruit extract (CPFE) from Opuntia ficus-indica (L.) Mill. has been investigated in carrageenininduced pleurisy, a rat model of acute inflammation. In our experimental design rat pleurisy was achieved by the injection of $0.2 \mathrm{ml}$ of $\lambda$-carrageenin in the pleural cavity. At selected time points, rats were sacrificed; cells recruited in pleura were counted and exudates collected to analyse inflammatory parameters such as NO, $\mathrm{PGE}_{2}$, IL-1及, TNF- $\alpha$. CPFE (in the range between 5 and $20 \mathrm{~g}$ fresh fruit equivalent/kg), orally given $30 \mathrm{~min}$ before the injection, time- and dose-dependently reduced the exudate volume (up to $72 \%$ ) and the number of leukocytes recruited in the pleural cavity (up to $96 \%$ ), at $24 \mathrm{~h}$. These anti-inflammatory effects were accompanied by an inhibited release of inflammatory mediators $\left(\mathrm{PGE}_{2}, \mathrm{NO}, \mathrm{IL}-1 \beta\right.$, TNF- $\alpha$ ). Our in vivo findings unveil for the first time an anti-inflammatory potential for cactus pear fruit and suggest further investigations to propose cactus pear fruit as a functional food able to improve health, possibly by preventing inflammationbased disorders.
\end{abstract}

\section{INTRODUCTION}

Age-related inflammation-based disorders such as cancer and cardiovascular disease are widely acknowledged to have a lower incidence among populations whose dietary habits include a large proportion of vegetal food, this providing various nonnutrient secondary metabolites (phytochemicals) with purported beneficial activities (Halliwell et al., 2005; Virgili and Marino, 2008). Then, in spite of the wealth of published papers, the interest in investigating how these food components may contribute to prevent and/or delay the development of such chronic processes is far from fading.

Inflammation is an adaptative response triggered by noxious stimuli and conditions, such as infection and tissue injury. At a very basic level, it involves recruitment of blood components, plasma and leukocytes, mainly neutrophils (PMN) to the site of infection or injury. This process is coordinated by a large range of biochemical mediators and results in the inflammatory exudate (Medzhitov, 2008). The acute phase of an inflammatory response successfully ends up in the elimination of the insult, followed by a resolution phase, mainly mediated by tissue-resident and recruited macrophages (MP).

Reactive oxygen and nitrogen species (RONS) are now acknowledged to exert a key role in maintaining normal cellular and tissue physiology, however may start signalling pathways involved in the development of a wide range of inflammation-based degenerative pathologies including cardiovascular and neuro-degenerative diseases, cancer, and aging itself (Wickens, 2001; Koutsilieri et al., 2002; Closa and Folch-Puy, 2004; Valko et al., 2006, 2007). RONS play a crucial role during the acute phase of the inflammatory response as they are i) released from PMN and MP in order to eliminate the pathogen at the site of inflammation, ii) involved in the synthesis of pro-inflammatory mediators such as prostaglandins (PG), nitric oxide, peroxynitrite, through both enzymatic and non-enzymatic free radical-catalysed reactions and iii) essential in the redox- 
dependent cell signalling of inflammatory cells (Basu, 2001). In this context, numerous phytochemicals with peculiar reducing properties that may effectively down-regulate the inflammatory response have recently been the object of research. First considered "health promoting" by virtue of their radical-scavenging activity and/or direct, antioxidant effects on cellular biomolecules, such compounds are now believed capable of interfering with the cell signal transduction by intercepting reactive species at the level of critical signalling pathways. In addition, interaction of these molecules with signalling enzymes, receptors and transcription factors has recently emerged (Leonarduzzi et al., 2001). Over the last ten years, nutritional studies on cactus pear fruit showed that its consumption positively affects the body's redox balance, decreases oxidative damage to lipids, and improves antioxidant status in healthy humans. Along these lines, chemical investigations demonstrated that the fruit is a interesting holder of antioxidative compounds: ascorbic acid and betalains among the most significant. The antioxidative effects in humans, however, appear to be linked to antioxdant components other than vitamin $\mathrm{C}$ and possibly to indicaxanthin: a phytochemical with the chemical structure of betalamic acid, the yellow cultivar of the fruit is particular enriched of.

A number of recent in vitro studies showed that indicaxanthin is a reducing and amphipathic molecule, able to penetrate cells and membranes and counteract oxidative damage (Butera et al., 2002; Tesoriere et al., 2003, 2005, 2006, 2007; Allegra et al., 2005; Liveri et al., 2007; Turco Liveri et al., 2009). In addition, it has been shown to act as a signalling molecule, being able to modulate specific redox-dependent pathways in cultured endothelial cells thus protecting them from dysfunction (Gentile et al., 2004). Remarkably, indicaxanthin is highly bioavailable in humans (Tesoriere et al., 2004) and does not appear to be metabolized neither during digestion, nor in liver (Khoo et al., 2001).

In this study we investigated the effects of the yellow cultivar of cactus pear fruit, orally given as an extract at nutritional relevant doses, in an in vivo model of acute inflammation: the carrageenin-induced rat pleurisy. This is widely accepted as a robust pharmacological model of inflammatory disease, used to test anti-inflammatory drugs (Di Rosa and Willoughby, 1971). A number of molecular markers of inflammation have been measured in order to ascertain the anti-inflammatoy potential of cactus pear fruit.

\title{
MATERIALS AND METHODS
}

\section{Reagents}

$\lambda$-Carragenan $(1 \% \mathrm{w} / \mathrm{v})$ was dissolved in sterile phosphate buffer saline (PBS). Unless otherwise specified, all the other reagents were from Sigma-Aldrich Co.

\section{Purification of Cactus Pear Fruit Extract}

CPFE was obtained from cactus pear (Opuntia ficus-indica) fruits (yellow cultivar) as previously reported (Butera et al., 2002; Stintzing et al., 2002). Fractions containing the extract were submitted to cryo-dessiccation and suspended in PBS for the animal experiments.

\begin{abstract}
Animals
Male Wistar rats (Harlan) weighing 175-200 g were used in all experiments. Rats were provided with food and water ad libitum. The light cycle was automatically controlled (on $7 \mathrm{am}$, off $7 \mathrm{pm}$ ) and the room temperature thermostatically regulated to $22 \pm 1^{\circ} \mathrm{C}$. Prior to the experiments rats were housed in these conditions for 3-4 days to become acclimatised. Animal care was in accordance with Italian and European regulations on the protection of rats used for experimental and other scientific purposes.
\end{abstract}

\section{Induction of Pleurisy and CPFE Treatment}

Induction of pleurisy was as previously described (Gilroy et al., 1999). Briefly, rats were slightly anaesthetised and $0.2 \mathrm{ml}$ of $1 \% \lambda$-carrageenin suspended in sterile 
saline solution were injected into the right pleural cavity (control). Rats were killed 4, 24 and $48 \mathrm{~h}$ later in an atmosphere of $\mathrm{CO}_{2}$. The exudate was harvested by washing each pleural cavity with $2 \mathrm{ml}$ of sterile saline containing $5 \mathrm{U} / \mathrm{ml}$ heparin. Any exudate with blood contamination was discarded. Each sample was centrifuged at $800 \mathrm{~g}$ for $10 \mathrm{~min}$ and cell pellet re-suspended in saline. Total cell count was estimated after trypan blue staining using a Burker counting chamber, whereas differential cell count was determined in smears by May-Grunwald staining. In parallel, groups of rats received CPFE $(5,10,20$ $\mathrm{mg}$ fresh fruit equivalent $/ \mathrm{kg}$ ) by oral gavage $30 \mathrm{~min}$ before carrageenin injection and every $8 \mathrm{~h}$ thereafter, up to $40 \mathrm{~h}$, with control rats receiving saline alone. Rats were killed at 4,24 and $48 \mathrm{~h}$ after carrageenin injection, and pleural exudates collected and processed as described above. Each experiment was carried out three times with groups of 10 rats.

\section{PGE $_{2}$, TNF- $\alpha$, IL-1 $\beta$ Determination}

Levels of $\mathrm{PGE}_{2}$, in the pleural exudates were measured using a 96-well based EIA kit from Cayman Chemicals (Inalco). Pro-inflammatory cytokines TNF- $\alpha$, IL-1 $\beta$ were evaluated using an ELISA kit from eBioscience.

\section{NOx Determination}

The amount of oxidation products from nitrite (NOx) in the inflammatory exudate was measured as previously described (Thomsen et al., 1991). Briefly, after reducing $\mathrm{NO}_{3}^{-}$to $\mathrm{NO}_{2}^{-}$using acid-washed cadmiun powder, $\mathrm{NO}_{2}^{-}$was evaluated using a spectrophotometric assay based on the Griess reaction (Kim et al., 1995).

\section{Data Handling and Statistical Analysis}

Data are expressed as mean \pm SEM of $n$ rats. Comparisons were made using oneway analysis of variance (ANOVA) followed by Bonferroni's test. Time-course comparisons including time, dose and dose $\mathrm{x}$ time in the model, were tested by two-way ANOVA. Differences between doses at each time level were assessed by Bonferroni's test (Instat-3 statistical software, GraphPad Software).

\section{RESULTS AND DISCUSSION}

\section{CPFE Counteracts the Acute Phase of Carrageenin-Induced Rat Pleurisy}

The pleural cavity of untreated rats comparable with those used in this work contains no exudate and physiological amounts of leukocytes, predominantly mononuclear ( $>97 \%$, Gilroy et al., 1999). Injection of $0.2 \mathrm{ml}$ of $\lambda$-carrageenin into the pleural cavity of rats (control) produced a clear time-dependent inflammatory response, evident as increase of both the exudate volume and the number of leukocyte migrated into the pleural cavity. In line with previously reported data (Gilroy et al., 1999), an increase of these parameters was observed at $4 \mathrm{~h}$, whereas the acute phase of inflammation peaked at $24 \mathrm{~h}$. The inflammatory response was shutdown at $48 \mathrm{~h}$ (Fig. 1). Differential cell count of leukocytes migrated into the pleural cavity showed that PMN dominated the early phase ( $4 \mathrm{~h})$ of the reaction ( $93 \%$ of PMN and $7 \%$ of monocytes, MC) and were replaced by $\mathrm{MC}(30 \%$ of PMN and $70 \%$ of MC) at $48 \mathrm{~h}$ (data not shown).

With respect to control rats, oral administration of CPFE (20 g fresh fruit equivalent $/ \mathrm{kg}$ ) $30 \mathrm{~min}$ before carrageenin injection, and then for $48 \mathrm{~h}$, at $8 \mathrm{~h}$ time intervals, significantly decreased the inflammatory response at all the time points considered (4-24-48 h), with inhibition of both the exudate volume and the total leukocyte number. The inhibitory effect at the peak of the inflammatory response accounted for more than 70 and $92 \%$, for the exudate volume and leukocyte number, respectively, and appeared greater than the inhibitory effects observed at 4 and $48 \mathrm{~h}$ (Fig. 1).

Carrageenin-treated rats were administered CPFE (5 to $20 \mathrm{~g}$ fresh fruit equivalent/kg) (Fig. 2). With respect to control, both the exudate volume (Fig. 2A) and the pleural leukocyte number (Fig. 2B) decreased significantly at $5 \mathrm{~g}$ fresh fruit equivalent $/ \mathrm{kg}$, with the maximum effect at $20 \mathrm{~mol} / \mathrm{kg}$ (70 and $95 \%$ inhibition of the 
exudate volume and pleural cell number, respectively). In parallel experiments carrageenin-treated rats were given indometacin as a reference anti-inflammatory drug (Gilroy et al., 1999), and the effect compared with rats administered CPFE at $20 \mathrm{~g}$ fresh fruit equivalent $/ \mathrm{kg}$. The extract exhibited the same effectiveness as indometacin at reducing the exudate volume $(n=30 ; \mathrm{p}=0.25$, Student's t test), and was even more effective at inhibiting the cell recruitment into the pleural cavity $(n=30 ; \mathrm{p}<0.0001$, Student's t test).

\section{CPFE Inhibits the Release of Pro-Inflammatory Mediators during Carrageenin- Induced Rat Pleurisy}

The release into the pleural cavity of a panel of pro-inflammatory soluble mediators supporting the acute phase of the inflammatory response (i.e., $\mathrm{PGE}_{2}$, NOx, IL1$\beta$ and TNF- $\alpha$ ) was then evaluated either in the absence or in the presence of CPFE supplementation. The injection of $0.2 \mathrm{ml}$ of $\lambda$-carrageenin into the pleural cavity of rats caused a release of $\mathrm{PGE}_{2}, \mathrm{NOx}, \mathrm{IL} 1-\beta$ and TNF- $\alpha$ at $24 \mathrm{~h}$. Inflammatory mediators are not detectable in rats before injection (32). Oral administration of CPFE (5 to $20 \mathrm{~g}$ fresh fruit equivalent $/ \mathrm{kg}$ ) dose-dependently decreased the release of all mediators (Fig. 3).

\section{CONCLUSIONS}

This study demonstrates remarkable pharmacological effects exerted by CPFE in an in vivo model of inflammatory condition and establishes for the first time a healthpromoting potential for cactus pear fruit, orally administered at nutritionally relevant doses.

\section{ACKNOWLEDGEMENTS}

M. Allegra and A. Ianaro designed research; M. Allegra, E. Panza and L. Tesoriere conducted research; M. Allegra, A. Ianaro and M.A. Livrea wrote the paper. M.A. Livrea had primary responsibility for final content. All authors read and approved the final manuscript.

\section{Literature Cited}

Allegra, M., Furtmuller, P.G., Jantschko, W., Zederbauer, M., Tesoriere, L., Livrea, M.A. and Obinger, C. 2005. Mechanism of interaction of betanin and indicaxanthin with human myeloperoxidase and hypochlorous acid. Biochem. Biophys. Res. Commun. 332:837-844.

Basu, S. 2001. Bioactive eicosanoids: role of prostaglandin F(2alpha) and F-isoprostanes in inflammation and oxidative stress related pathology. Mol. Cells 30:383-391.

Butera, D., Tesoriere, L., Di Gaudio, F., Bongiorno, A., Allegra, M., Pintaudi, A.M., Kohen, R. and Livrea, M.A. 2002. Antioxidant activities of sicilian prickly pear (Opuntia ficus indica) fruit extracts and reducing properties of its betalains: betanin and indicaxanthin. J. Agric. Food Chem. 50:6895-6901.

Closa, D. and Folch-Puy, E. 2004. Oxygen free radicals and the systemic inflammatory response. IUBMB Life 56:185-191.

Di Rosa, M. and Willoughby, D.A. 1971. Screens for anti-inflammatory drugs. J. Pharm. Pharmacol. 23:297-298.

Gentile, C., Tesoriere, L., Allegra, M., Livrea, M.A. and D’Alessio, P. 2004. Antioxidant betalains from cactus pear (Opuntia ficus-indica) inhibit endothelial ICAM-1 expression. Ann N Y Acad Sci. 1028:481-486.

Gilroy, D.W., Colville-Nash, P.R., Willis, D., Chivers, J., Paul-Clark, M.J. and Willoughby, D.A. 1999. Inducible cyclooxygenase may have anti-inflammatory properties. Nat. Med. 5:698-701.

Halliwell, B., Rafter, J. and Jenner, A. 2005. Health promotion by flavonoids, tocopherols, tocotrienols, and other phenols: direct or indirect effects? Antioxidant or not? Am. J. Clin. Nutr. 81:268S-276S.

Khoo, K.F., Tan, H.J. and Raymond, A.A. 2001. Prevalence of depression in stroke 
patients with vascular dementia in universiti kebangsaan malaysia medical center. Med. J. Malaysia 68:105-110.

Kim, H., Lee, H.S., Chang, K.T., Ko, T.H., Baek, K.J. and Kwon, N.S. 1995. Chloromethyl ketones block induction of nitric oxide synthase in murine macrophages by preventing activation of nuclear factor-kappa B. J. Immunol. 154:4741-4748.

Koutsilieri, E., Scheller, C., Grunblatt, E., Nara, K., Li, J. and Riederer, P. 2002. Free radicals in Parkinson's disease. J. Neurol. 249 Suppl 2:II1-5.

Leonarduzzi, G., Sottero, B. and Poli, G. 2001. Targeting tissue oxidative damage by means of cell signaling modulators: the antioxidant concept revisited. Pharmacol. Ther. 128:336-374.

Liveri, M.L., Sciascia, L., Lombardo, R., Tesoriere, L., Passante, E. and Livrea, M.A. 2007. Spectrophotometric evidence for the solubilization site of betalain pigments in membrane biomimetic systems. J. Agric. Food Chem. 55:2836-2840.

Medzhitov, R. 2008. Origin and physiological roles of inflammation. Nature 454:428435.

Stintzing, F.C., Schieber, A. and Carle, R. 2002. Identification of betalains from yellow beet (Beta vulgaris L.) and cactus pear [Opuntia ficus-indica (L.) Mill.] by highperformance liquid chromatography-electrospray ionization mass spectrometry. J. Agric. Food Chem. 50:2302-2307.

Tesoriere, L., Butera, D., D’Arpa, D., Di Gaudio, F., Allegra, M., Gentile, C. and Livrea, M.A. 2003. Increased resistance to oxidation of betalain-enriched human low density lipoproteins. Free Radic. Res. 37:689-696.

Tesoriere, L., Allegra, M., Butera, D. and Livrea, M.A. 2004. Absorption, excretion, and distribution of dietary antioxidant betalains in LDLs: potential health effects of betalains in humans. Am. J. Clin. Nutr. 80:941-945.

Tesoriere, L., Butera, D., Allegra, M., Fazzari, M. and Livrea, M.A. 2005. Distribution of betalain pigments in red blood cells after consumption of cactus pear fruits and increased resistance of the cells to ex vivo induced oxidative hemolysis in humans. J. Agric. Food Chem. 53:1266-1270.

Tesoriere, L., Allegra, M., Butera, D., Gentile, C. and Livrea, M.A. 2006. Cytoprotective effects of the antioxidant phytochemical indicaxanthin in beta-thalassemia red blood cells. Free Radic. Res. 40:753-761.

Tesoriere, L., Allegra, M., Butera, D., Gentile, C. and Livrea, M.A. 2007. Kinetics of the lipoperoxyl radical-scavenging activity of indicaxanthin in solution and unilamellar liposomes. Free Radic Res. 41:226-233.

Thomsen, L.L., Ching, L.M., Zhuang, L., Gavin, J.B. and Baguley, B.C. 1991 Tumordependent increased plasma nitrate concentrations as an indication of the antitumor effect of flavone-8-acetic acid and analogues in mice. Cancer Res. 51:77-81.

Turco Liveri, M.L., Sciascia, L., Allegra, M., Tesoriere, L. and Livrea, M.A. 2009. Partition of indicaxanthin in membrane biomimetic systems. A kinetic and modeling approach. J. Agric. Food Chem. 57:10959-10963.

Valko, M., Rhodes, C.J., Moncol, J., Izakovic, M. and Mazur, M. 2006. Free radicals, metals and antioxidants in oxidative stress-induced cancer. Chem. Biol. Interact. 160:1-40.

Valko, M., Leibfritz, D., Moncol, J., Cronin, M.T., Mazur, M. and Telser, J. 2007. Free radicals and antioxidants in normal physiological functions and human disease. Int. J. Biochem. Cell Biol. 39:44-84.

Virgili, F. and Marino, M. 2008. Regulation of cellular signals from nutritional molecules: a specific role for phytochemicals, beyond antioxidant activity. Free Radic Biol Med. 45:1205-1216.

Wickens, A.P. 2001. Ageing and the free radical theory. Respir. Physiol. 128:379-391. 


\section{Figures}
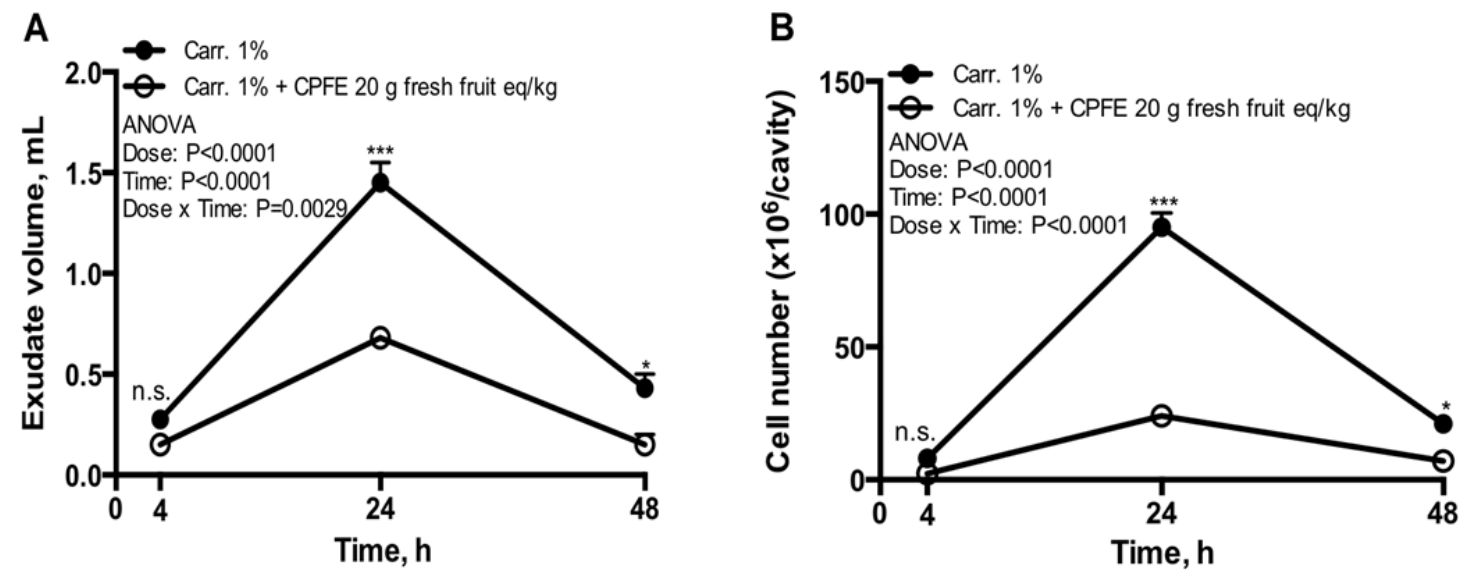

Fig. 1. Effect of CPFE on the time-course of exudate formation (A) and leukocyte infiltration (B) in carrageenin-induced rat pleurisy. Each point is the mean $\pm \mathrm{SEM}$, $n=30$ (10 rats in three separate experiments). Dose differences at each time level were assessed by Bonferroni's (test; ns $=$ non-significant; $* \mathrm{P}=0.0169$; $* * * \mathrm{P}<0.0001$. Carr: carrageenin).
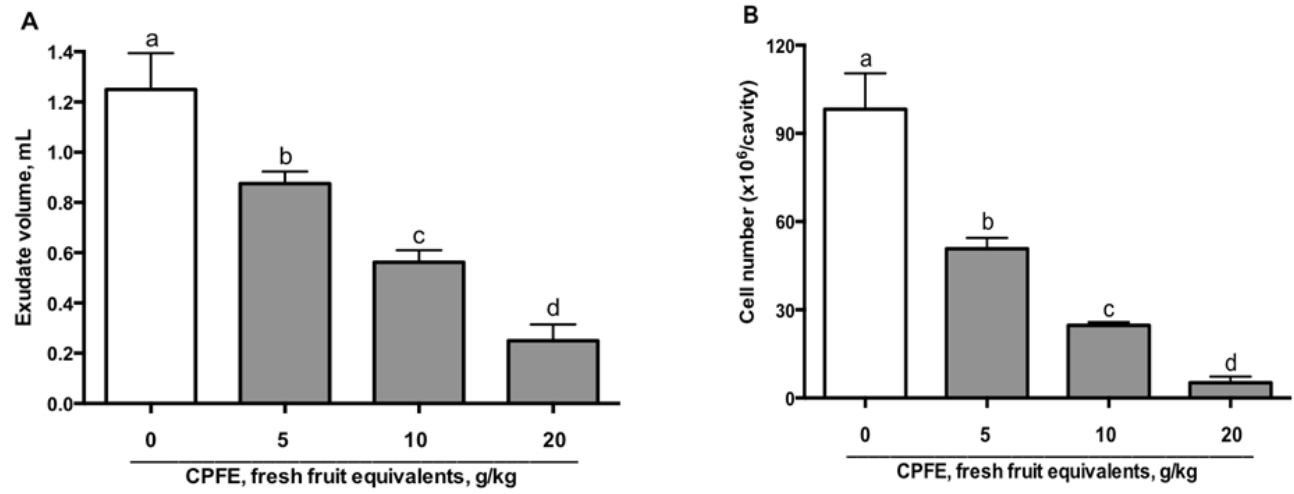

Fig. 2. Exudate volume (A) and leukocyte infiltration (B) at $24 \mathrm{~h}$ in carrageenin-treated rats administered CPFE, 5-20 g fresh fruit equivalent $/ \mathrm{kg}$. Each point is the mean \pm SEM, $n=30$ (10 rats in three separate experiments). Labeled means without a common letter differ, $P<0.05$. 
A

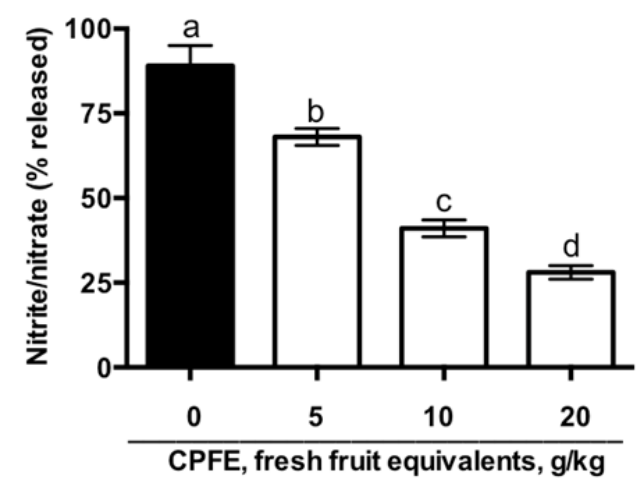

C

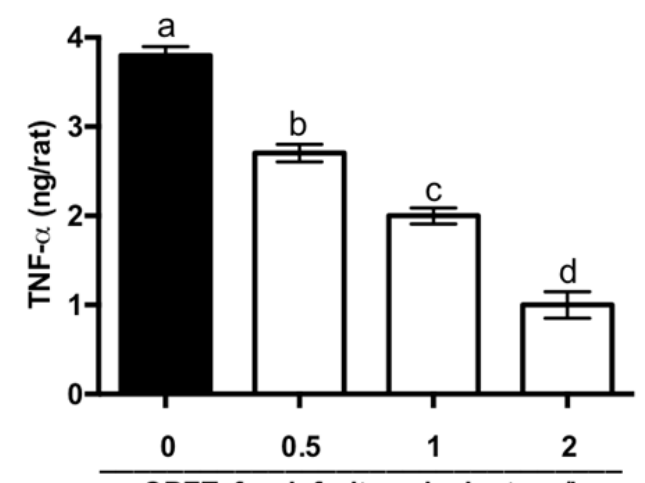

CPFE, fresh fruit equivalents, $\mathrm{g} / \mathrm{kg}$
B

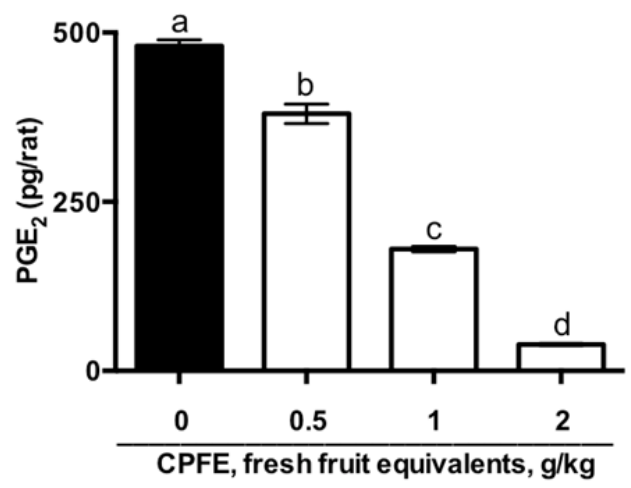

D

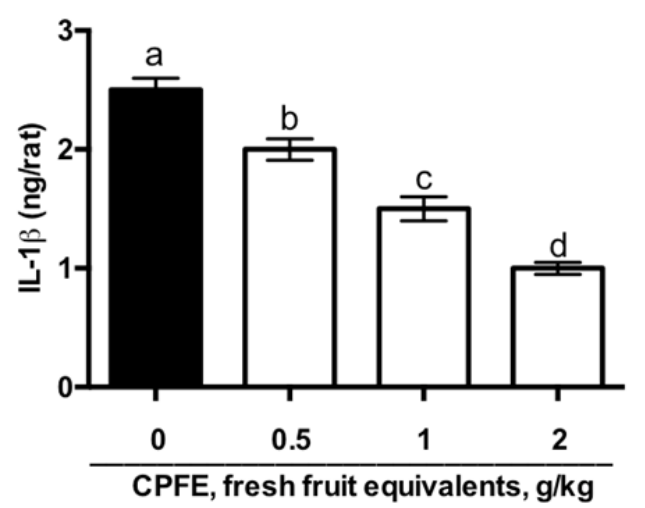

Fig. 3. Release of pro-inflammatory mediators NOx (A), $\mathrm{PGE}_{2}$ (B), TNF- $\alpha$ (C), IL-1 $\beta$ (D) at $24 \mathrm{~h}$ in carrageenin-treated rats administered CPFE, 5-20 $\mathrm{g}$ fresh fruit equivalent $/ \mathrm{kg}$. Each point is the mean $\pm \mathrm{SEM}, n=30$ (10 rats in three separate experiments). Labeled means without a common letter differ, $P<0.05$. 
